\title{
Pneumomediastinum and subcutaneous emphysema in COVID-19: barotrauma or lung frailty?
}

Daniel H.L. Lemmers (10 1,2,6, Mohammed Abu Hilal ${ }^{1,6}$, Claudio Bnà ${ }^{3}$, Chiara Prezioso ${ }^{4,5}$, Erika Cavallo ${ }^{4,5}$, Niccolò Nencini $\mathbb{1}^{4,5}$, Serena Crisci ${ }^{4,5}$, Federica Fusina $\mathbb{Q}^{4}$ and Giuseppe Natalini ${ }^{4}$

\section{ABSTRACT}

Background: In mechanically ventilated acute respiratory distress syndrome (ARDS) patients infected with the novel coronavirus disease (COVID-19), we frequently recognised the development of pneumomediastinum and/or subcutaneous emphysema despite employing a protective mechanical ventilation strategy. The purpose of this study was to determine if the incidence of pneumomediastinum/subcutaneous emphysema in COVID-19 patients was higher than in ARDS patients without COVID-19 and if this difference could be attributed to barotrauma or to lung frailty.

Methods: We identified both a cohort of patients with ARDS and COVID-19 (CoV-ARDS), and a cohort of patients with ARDS from other causes (noCoV-ARDS).

Patients with CoV-ARDS were admitted to an intensive care unit (ICU) during the COVID-19 pandemic and had microbiologically confirmed severe acute respiratory syndrome coronavirus 2 (SARS-CoV-2) infection. NoCoV-ARDS was identified by an ARDS diagnosis in the 5 years before the COVID-19 pandemic period.

Results: Pneumomediastinum/subcutaneous emphysema occurred in 23 out of 169 (13.6\%) patients with CoV-ARDS and in three out of $163(1.9 \%)$ patients with noCoV-ARDS ( $p<0.001)$. Mortality was $56.5 \%$ in CoV-ARDS patients with pneumomediastinum/subcutaneous emphysema and $50 \%$ in patients without pneumomediastinum $(\mathrm{p}=0.46)$.

CoV-ARDS patients had a high incidence of pneumomediastinum/subcutaneous emphysema despite the use of low tidal volume $\left(5.9 \pm 0.8 \mathrm{~mL} \cdot \mathrm{kg}^{-1}\right.$ ideal body weight) and low airway pressure (plateau pressure $23 \pm 4 \mathrm{cmH}_{2} \mathrm{O}$ ).

Conclusions: We observed a seven-fold increase in pneumomediastinum/subcutaneous emphysema in CoV-ARDS. An increased lung frailty in CoV-ARDS could explain this finding more than barotrauma, which, according to its etymology, refers to high transpulmonary pressure.

@ERSpublications

Pneumomediastinum is more frequent in \#COVID19 patients with ARDS despite the use of a protective ventilatory approach. Lung frailty, and not barotrauma, appears to be the main cause of this finding. https://bit.ly/36FQe03

Cite this article as: Lemmers DHL, Abu Hilal M, Bnà C, et al. Pneumomediastinum and subcutaneous emphysema in COVID-19: barotrauma or lung frailty? ERJ Open Res 2020; 6: 003852020 [https://doi.org/10.1183/23120541.00385-2020].

\section{Availability of data and material: The datasets generated during and/or analysed during the current study are available} from the corresponding author on reasonable request.

Received: 15 June 2020 | Accepted after revision: 14 Sept 2020

Copyright $\odot$ ERS 2020. This article is open access and distributed under the terms of the Creative Commons Attribution Non-Commercial Licence 4.0. 


\section{Introduction}

Since the beginning of the novel coronavirus disease 2019 (COVID-19) outbreak in Lombardy, Italy, the Fondazione Poliambulanza Hospital has treated over 2200 affected patients, and over 160 of them were admitted to the intensive care unit (ICU) for treatment of acute respiratory distress syndrome (ARDS) secondary to COVID-19.

All patients admitted to ICU underwent invasive mechanical ventilation with protective criteria aimed at preventing ventilator-induced lung injury. The current approach to protective ventilation, which became universally accepted after the ARDS Network trial [1], is based on the reduction of tidal volume to about $6 \mathrm{~mL} \cdot \mathrm{kg}^{-1}$ of ideal body weight while maintaining the airway plateau pressure below $30 \mathrm{cmH}_{2} \mathrm{O}$ [2]. In the last two decades, as a consequence of this strategy, the occurrence of the main macroscopic signs of barotrauma such as pneumothorax, pneumomediastinum and subcutaneous emphysema have become very rare [3]. In fact, this type of damage had been rarely seen in our ICU patients with ARDS. Nonetheless, during the COVID-19 pandemic there seemed to be a remarkable increase in pneumomediastinum/ subcutaneous emphysema occurrence despite the use of the same unchanged protective mechanical ventilation protocol. A decrease in lung compliance, age and underlying lung disease (such as interstitial lung disease, chronic obstructive pulmonary disease cystic fibrosis, and certain lung infections like Pneumocystis jirovecii pneumonia) are known risk factors for non-trauma related pneumomediastinum [4], Yet the causes of the apparent increase in pneumomediastinum and subcutaneous emphysema in our COVID-19 patients were not clear. The purpose of this study was to determine if the incidence of pneumomediastinum/subcutaneous emphysema in mechanically ventilated COVID-19 patients admitted to ICU was higher than that in ARDS patients without COVID-19, and whether this could be attributed to barotrauma or rather to lung frailty.

\section{Material and methods}

\section{Study design and participants}

The referral Ethics Committee approved a waiver of consent from individual patients due to the retrospective nature of the study. Inclusion criteria were: 1) age older than 18 years, 2) ARDS diagnosis at ICU admission [5] and 3) invasive mechanical ventilation.

Two cohorts were created. The first cohort included patients with ARDS [5] and COVID-19 (CoV-ARDS) who were admitted to the ICU from the beginning of the COVID-19 pandemic in Italy. We considered the pandemic period as starting on February 18, 2020, which was the day of the first diagnosis of severe acute respiratory syndrome coronavirus 2 (SARS-CoV-2) infection in an Italian patient. SARS-CoV-2 infection was diagnosed with a positive real-time reverse transcriptase PCR test for SARS-CoV-2 on biological samples. Patients admitted until April 15, 2020 were included in the study. The second cohort included patients between January 2015, and December 2019, admitted to the ICU with an ARDS diagnosis [5], before the beginning of the COVID-19 pandemic period in Italy (noCoV-ARDS).

All data and variables were extracted from the electronic patient registry. The diagnosis of pneumomediastinum/subcutaneous emphysema was confirmed by computed tomography (CT) scan or chest radiograph.

\section{Outcome measures and explanatory variables}

The outcome variable was the incidence of pneumomediastinum/subcutaneous emphysema in patients with ARDS secondary to COVID-19. Response variables were patient-related characteristics such as age, sex, body mass index and comorbidities, and characteristics related to acute respiratory failure and mechanical ventilation, such as positive end-expiratory pressure (PEEP) $\left(\mathrm{cmH}_{2} \mathrm{O}\right)$, peak airway pressure $\left(\mathrm{cmH}_{2} \mathrm{O}\right)$, plateau airway pressure $\left(\mathrm{cmH}_{2} \mathrm{O}\right), \mathrm{pH}$, arterial carbon dioxide tension $\left(P_{\mathrm{aCO}_{2}}\right)(\mathrm{mmHg})$, arterial oxygen tension $\left(\mathrm{P}_{\mathrm{aO}_{2}}\right)$ /inspiratory oxygen fraction $\left(\mathrm{F}_{\mathrm{IO}_{2}}\right)(\mathrm{mmHg})$, compliance of the respiratory system $\left(\mathrm{mL} \cdot \mathrm{cmH}_{2} \mathrm{O}^{-1}\right)$, minute ventilation $\left(\mathrm{L} \cdot \mathrm{min}^{-1}\right)$, corrected minute ventilation $\left(\mathrm{L} \cdot \mathrm{min}^{-1}\right)$ and tidal volume/ ideal body weight $\left(\mathrm{mL} \cdot \mathrm{kg}^{-1}\right)$. Corrected minute ventilation, an indirect estimation of dead space, was calculated as minute ventilation $\times P_{\mathrm{aCO}_{2}} / 40$. [5].

Affiliations: 'Dept of Surgery, Fondazione Poliambulanza, Brescia, Italy. ${ }^{2}$ Dept of Surgery, Amsterdam UMC, Cancer Center Amsterdam, University of Amsterdam, Amsterdam, the Netherlands. ${ }^{3}$ Dept of Radiology, Fondazione Poliambulanza, Brescia, Italy. ${ }^{4}$ Dept of Anesthesia and Intensive Care, Fondazione Poliambulanza, Brescia, Italy. ${ }^{5}$ Dept of Anesthesiology and Intensive Care Medicine, Catholic University of The Sacred Heart, Rome, Italy. ${ }^{6}$ These authors contributed equally.

Correspondence: Giuseppe Natalini, Dept of Anesthesia and Intensive Care, Istituto Fondazione Poliambulanza, Via Bissolati 57, 25124, Brescia, Italy. E-mail: giuseppe.natalinidpoliambulanza.it 


\section{Statistical analysis}

Variables were presented with frequencies and percentages for categorical variables, as median (1st-3rd quartile) for non-normal distributed continuous variables and as mean \pm standard deviation for normal distributed continuous variables. The difference in explanatory variables was assessed using a Chi-squared test or Fisher test for dichotomous and categorical variables, a t-test for normally distributed continuous variables, and a Mann-Whitney $U$ test for non-normal distributed continuous variables. A p-value lower than 0.05 was considered significant. Statistical analyses were performed with R 3.6.3 (R Core Team, 2020; R Foundation for Statistical Computing, Vienna, Austria).

\section{Results}

\section{Baseline characteristics}

One hundred and sixty-nine CoV-ARDS patients and 163 noCoV-ARDS patients were included in this study. Patients' characteristics are shown in table 1.

Patients with CoV-ARDS were younger, more frequently male, with a higher body mass index, with a lower prevalence of diabetes mellitus and chronic obstructive pulmonary disease than noCoV-ARDS patients. Pneumomediastinum/subcutaneous emphysema incidence, and in-hospital mortality were higher in CoV-ARDS than in noCoV-ARDS patients. CoV-ARDS patients were ventilated with a higher PEEP, and lower tidal volume/ideal body weight than noCoV-ARDS patients. Compliance of the respiratory system, and $P_{\mathrm{aO}_{2}} / F_{\mathrm{IO}_{2}}$ were lower in CoV-ARDS patients, whereas corrected minute ventilation was higher when compared to noCoV-ARDS. $P_{\mathrm{aCO}_{2}}$ was higher in CoV-ARDS than in noCoV-ARDS patients, as a result of similar minute ventilation in the presence of increased dead space estimation.

\section{Pneumomediastinum/subcutaneous emphysema}

Twenty-three of the 169 patients admitted to ICU with CoV-ARDS developed pneumomediastinum/ subcutaneous emphysema. The characteristics of patients with and without pneumomediastinum/ subcutaneous emphysema in CoV-ARDS on the day of ICU admission are shown in table 2 . The only significant difference between patients with and without pneumomediastinum/subcutaneous emphysema was a lower minute ventilation on the day of ICU admission in patients with pneumomediastinum/

TABLE 1 Baseline characteristics on first day of mechanical ventilation and outcomes in patients with acute respiratory distress syndrome (ARDS) secondary to novel coronavirus disease (COVID-19) and ARDS from other diseases

\begin{tabular}{|c|c|c|c|}
\hline Variables & CoV-ARDS & noCoV-ARDS & p-value \\
\hline Subjects $\mathrm{n}$ & 169 & 163 & \\
\hline Age years & $66(59-71)$ & $72(62-78)$ & $<0.001$ \\
\hline Male sex & $133(78.7)$ & $106(65.4)$ & 0.007 \\
\hline Body mass index $\mathrm{kg} \cdot \mathrm{m}^{-2}$ & $28(25-31)$ & $27(24-31)$ & 0.02 \\
\hline Diabetes mellitus & $26(15.4)$ & $47(29)$ & 0.003 \\
\hline Arterial hypertension & 90 (53.3) & 96 (59.3) & 0.27 \\
\hline COPD & $4(2.4)$ & 22 (13.5) & $<0.001$ \\
\hline Positive end-expiratory pressure $\mathrm{cmH}_{2} \mathrm{O}$ & $12(10-14)$ & $8(5-9)$ & $<0.001$ \\
\hline Peak airway pressure $\mathrm{cmH}_{2} \mathrm{O}$ & $30 \pm 5$ & $22 \pm 6$ & $<0.001$ \\
\hline Plateau airway pressure $\mathrm{cmH}_{2} \mathrm{O}$ & $23 \pm 4$ & $19 \pm 3$ & $<0.001$ \\
\hline $\mathrm{pH}$ & $7 \cdot 29 \pm 0.12$ & $7 \cdot 33 \pm 0.14$ & 0.15 \\
\hline$P_{\mathrm{aCO}}, \mathrm{mmHg}$ & $56 \pm 16$ & $46 \pm 12$ & $<0.001$ \\
\hline Compliance of the respiratory system $\mathrm{mL} \cdot \mathrm{cmH}_{2} \mathrm{O}^{-1}$ & $28(22-34)$ & $35(25-43)$ & $<0.001$ \\
\hline Minute ventilation L· $\min ^{-1}$ & $8.8 \pm 1.3$ & $8.7 \pm 2.3$ & 0.62 \\
\hline Corrected minute ventilation L. $\min ^{-1}$ & $12.4(9.3-15)$ & $9.6(7.5-11.8)$ & $<0.001$ \\
\hline$P_{\mathrm{aO}_{2}} / F_{1 \mathrm{O}_{2}} \mathrm{mmHg}$ & $111(86-153)$ & $140(100-198)$ & $<0.001$ \\
\hline Tidal volume/ideal body weight $\mathrm{mL} \cdot \mathrm{kg}^{-1}$ & $5.9 \pm 0.8$ & $6.6 \pm 1.3$ & $<0.001$ \\
\hline Length of stay in intensive care unit & $10(5-18)$ & $7(3-20)$ & 0.22 \\
\hline Length of stay in hospital & $15(9-24)$ & $20(11-33)$ & 0.002 \\
\hline In-hospital mortality & $86(50.9)$ & $43(26.6)$ & $<0.001$ \\
\hline Pneumomediastinum/subcutaneous emphysema & $23(13.6)$ & $3(1.9)$ & $<0.001$ \\
\hline
\end{tabular}


TABLE 2 Baseline characteristics and outcomes in patients with acute respiratory distress syndrome (ARDS) secondary to novel coronavirus disease (COVID-19) with and without pneumomediastinum/subcutaneous emphysema (P/SE)

\begin{tabular}{|c|c|c|c|}
\hline Variables & Without P/SE & With P/SE & p-value \\
\hline Subjects $\mathbf{n}$ & 146 & 23 & \\
\hline Age years & $67(59-71)$ & $64(60-70)$ & 0.24 \\
\hline Male sex & $118(80.8)$ & $15(65)$ & 0.09 \\
\hline Body mass index $\mathrm{kg} \cdot \mathrm{m}^{-2}$ & $28(26-31)$ & $27(25-31)$ & 0.29 \\
\hline Diabetes mellitus & $23(15.8)$ & $3(13)$ & 0.74 \\
\hline Arterial hypertension & 79 (54.1) & $11(47.8)$ & 0.58 \\
\hline COPD & $4(2.7)$ & $0(0)$ & 1 \\
\hline Positive end-expiratory pressure $\mathrm{cmH}_{2} \mathrm{O}$ & $12(10-14)$ & $12(8-15)$ & 0.72 \\
\hline Peak airway pressure $\mathrm{cmH}_{2} \mathrm{O}$ & $29 \pm 5$ & $30 \pm 5$ & 0.56 \\
\hline Plateau airway pressure $\mathrm{cmH}_{2} \mathrm{O}$ & $23 \pm 4$ & $24 \pm 6$ & 0.80 \\
\hline $\mathrm{pH}$ & $7.28 \pm 0.12$ & $7.33 \pm 0.11$ & 0.07 \\
\hline$P_{\text {aco }}, \mathrm{mmHg}$ & $57 \pm 16$ & $53 \pm 15$ & 0.26 \\
\hline Compliance of the respiratory system $\mathrm{mL} \cdot \mathrm{cmH}_{2} \mathrm{O}^{-1}$ & $27(22-33)$ & $28(22-36)$ & 0.55 \\
\hline Minute ventilation L- $\min ^{-1}$ & $8.9 \pm 1.3$ & $8.3 \pm 1.1$ & 0.04 \\
\hline Corrected minute ventilation $\mathrm{L} \cdot \mathrm{min}^{-1}$ & $12.7(9.4-15)$ & $9.9(8.4-13.1)$ & 0.07 \\
\hline $\mathrm{P}_{\mathrm{aO}_{2}} / F_{1 \mathrm{O}_{2}} \mathrm{mmHg}$ & $114(86-153)$ & 105 (81-137) & 0.21 \\
\hline Tidal volume/ideal body weight $\mathrm{mL} \cdot \mathrm{kg}^{-1}$ & $5.9 \pm 0.8$ & $6.1 \pm 0.9$ & 0.23 \\
\hline Length of stay in intensive care unit & $9(5-18)$ & $11(6-21)$ & 0.44 \\
\hline Length of stay in hospital & $14(8-23)$ & $18(12-28)$ & 0.18 \\
\hline In-hospital mortality & $73(50)$ & $13(56.5)$ & 0.46 \\
\hline
\end{tabular}

Data are presented as median (interquartile range), $\mathrm{n}(\%)$ or mean $\pm \mathrm{SD}$, unless otherwise stated. $P_{\mathrm{aCO}}$ : arterial carbon dioxide tension; $P_{\mathrm{aO}}$ : arterial oxygen tension; $F_{\mathrm{IO}_{2}}$ : inspiratory oxygen fraction.

subcutaneous emphysema. No difference in PEEP, plateau pressure, tidal volume/ideal body weight and compliance were observed.

Table 3 compares mechanical ventilation and gas exchange data on the day of ICU admission and on the day of pneumomediastinum/subcutaneous emphysema occurrence for the $23 \mathrm{CoV}$-ARDS patients who developed pneumomediastinum. PEEP and plateau pressure were lower on the day on which pneumomediastinum/subcutaneous emphysema developed than on the day of ICU admission, and tidal volume was slightly increased. The average day of appearance of pneumomediastinum/subcutaneous emphysema for CoV-ARDS patients was 3.5 (0.25-7.75) days.

TABLE 3 Ventilatory variables of patients with acute respiratory distress syndrome (ARDS) secondary to novel coronavirus disease (COVID-19) who developed pneumomediastinum/ subcutaneous emphysema $(n=23)$

\begin{tabular}{|c|c|c|c|}
\hline Variables & $\begin{array}{l}\text { On the first day of mechanical } \\
\text { ventilation }\end{array}$ & $\begin{array}{c}\text { On the day of } \\
\text { P/SE }\end{array}$ & p-value \\
\hline Positive end-expiratory pressure $\mathrm{cmH}_{2} \mathrm{O}$ & $12(8-15)$ & $9(6-13)$ & 0.002 \\
\hline Peak airway pressure $\mathrm{cmH}_{2} \mathrm{O}$ & $30 \pm 5$ & $29 \pm 5$ & 0.08 \\
\hline Plateau airway pressure $\mathrm{cmH}_{2} \mathrm{O}$ & $24 \pm 5$ & $22 \pm 4$ & 0.045 \\
\hline $\mathrm{pH}$ & $7.32 \pm 0.09$ & $7.33 \pm 0.13$ & 0.4 \\
\hline$P_{\mathrm{aCO}_{2}} \mathrm{mmHg}$ & $54 \pm 14$ & $53 \pm 12$ & 0.77 \\
\hline $\begin{array}{l}\text { Compliance of the respiratory system } \\
\mathrm{mL} \cdot \mathrm{cm} \mathrm{H}_{2} \mathrm{O}^{-1}\end{array}$ & $25(22-34)$ & $33(27-40)$ & 0.13 \\
\hline Minute ventilation $L \cdot \min ^{-1}$ & $8.4 \pm 1.2$ & $8.9 \pm 2.1$ & 0.13 \\
\hline Corrected minute ventilation L.min ${ }^{-1}$ & $11.5 \pm 4$ & $12.1 \pm 4.1$ & 0.45 \\
\hline$P_{\mathrm{aO}_{2}} / F_{\mathrm{IO}_{2}} \mathrm{mmHg}$ & $108 \pm 33$ & $131 \pm 76$ & 0.13 \\
\hline Tidal volume/ideal body weight $\mathrm{mL} \cdot \mathrm{kg}^{-1}$ & $6 \pm 0.9$ & $6.7 \pm 1.7$ & 0.008 \\
\hline \multicolumn{4}{|c|}{$\begin{array}{l}\text { Data are presented as median (interquartile range) or mean } \pm \mathrm{SD} \text {, unless otherwise stated. } \mathrm{P} / \mathrm{SE} \text { : } \\
\text { pneumomediastinum/subcutaneous emphysema; } P_{\mathrm{aCO}_{2}} \text { : arterial carbon dioxide tension; } P_{\mathrm{aO}_{2}} \text { : arterial } \\
\text { oxygen tension; } F_{\mathrm{IO}_{2}} \text { : inspiratory oxygen fraction. }\end{array}$} \\
\hline
\end{tabular}




\section{Discussion}

To the best of our knowledge, this study represents to date the largest cohort of patients who developed pneumomediastinum/subcutaneous emphysema. The occurrence of pneumomediastinum/subcutaneous emphysema was rare in noCOV-ARDS but was more frequent in CoV-ARDS even if the same protective ventilatory approach was applied.

The causes of pneumomediastinum in mechanically ventilated patients can be multifactorial [4]. Pulmonary barotrauma in patients with ARDS has traditionally been related to the development of high airway pressure associated with high tidal volume ventilation $\left(\sim 12 \mathrm{~mL} \cdot \mathrm{kg}^{-1}\right.$ ideal body weight) [6-8].

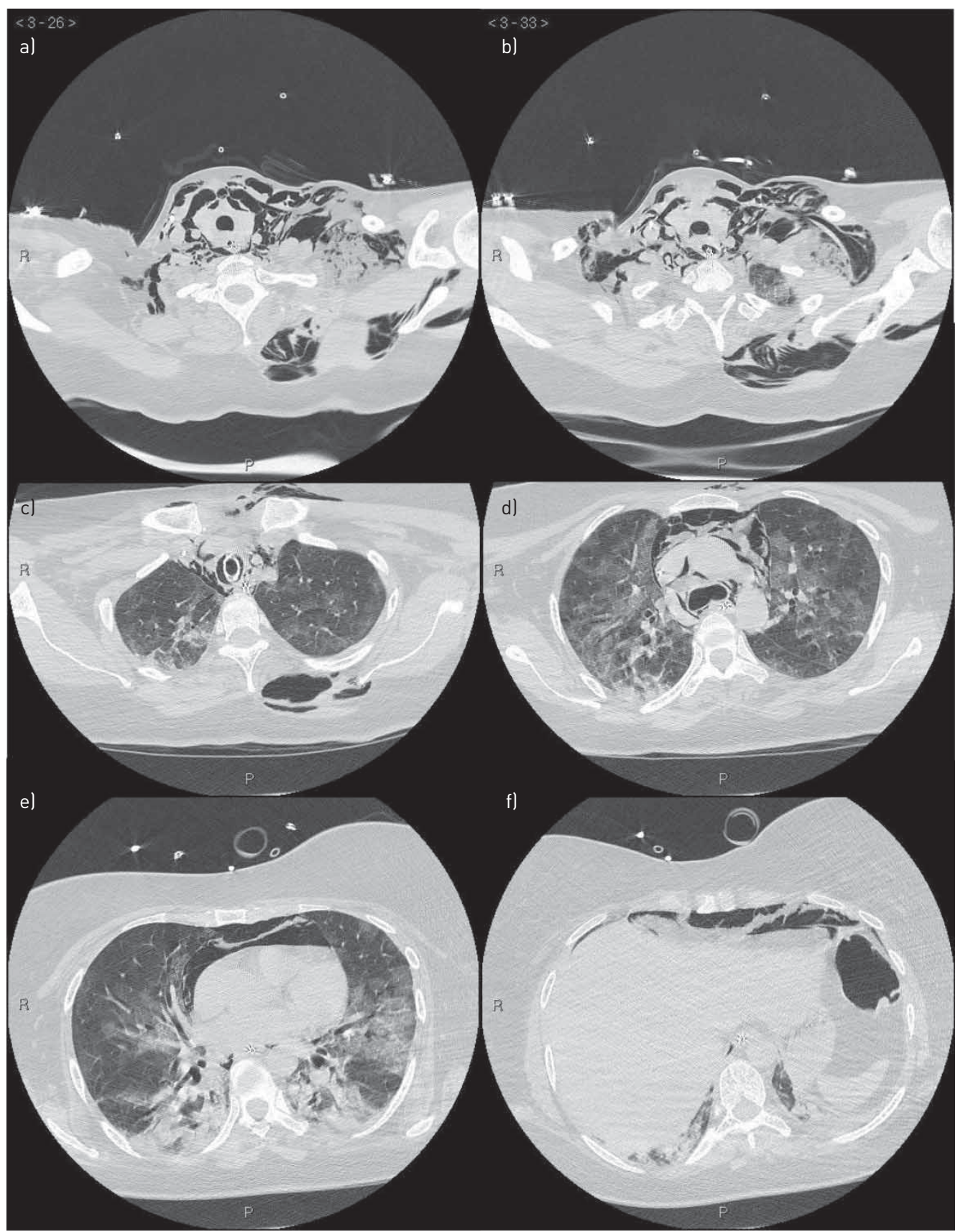

FIGURE 1 Chest computed tomography scan, performed in a patient with multiple ground-glass lesions and infiltrates (acute respiratory distress syndrome (ARDS) secondary to novel coronavirus disease 2019). The scan shows the Macklin effect due to alveolar rupture, air leakage and dissection along bronchovascular sheaths with pulmonary interstitial emphysema and pneumomediastinum, that extends widely along the muscle bundles of the chest and neck. A subcutaneous emphysema and extension of pneumomediastinum in the abdomen is also seen. 
Despite the fact that airway pressure in CoV-ARDS patients was higher than that in noCoV-ARDS, the criteria of protective ventilation were respected in CoV-ARDS patients as well. Indeed, in CoV-ARDS patients, average plateau pressure was $23 \mathrm{cmH}_{2} \mathrm{O}$, a value lower than the threshold of $30 \mathrm{cmH}_{2} \mathrm{O}$ recommended by current guidelines [2] and lower than the average $26 \mathrm{cmH}_{2} \mathrm{O}$ recorded at the onset of severe ARDS in the LUNG SAFE study patients [2, 9]. Moreover, tidal volume was lower $\left(5.9 \mathrm{~mL} \cdot \mathrm{kg}^{-1}\right.$ ideal body weight on average) than what has been previously found $\left(7.5 \mathrm{~mL} \cdot \mathrm{kg}^{-1}\right.$ ideal body weight on average in the LUNG SAFE patients [9]) and in line with guidelines [2]. In the CoV-ARDS cohort, patients who developed pneumomediastinum/subcutaneous emphysema had similar airway pressure on the day of ICU admission to patients who did not develop it. Moreover, airway pressures were lower on the day pneumomediastinum/subcutaneous emphysema was noticed than on the day on which mechanical ventilation was started.

Considering this, pneumomediastinum/subcutaneous emphysema in CoV-ARDS does not appear to be associated with the classic barotrauma mechanism, which, according to its etymology, refers only to high transpulmonary pressures [10]. This is in agreement with a previously published study on $>5000$ mechanically ventilated patients, in which the presence of air outside the tracheobronchial tree (pneumothorax, pneumomediastinum, subcutaneous emphysema) was unrelated to airway pressures and tidal volume [11]. Therefore, the automatic association between barotrauma and presence of air outside the tracheobronchial tree in mechanically ventilated patients $[11,12]$ should be reconsidered. Actually, the term "barotrauma" should be used in presence of air outside the tracheobronchial tree only when concurrent with elevated airway pressure. In its absence, such a condition should not be referred to as barotrauma, but simply described for what it is (pneumomediastinum, subcutaneous emphysema, pneumothorax). Whenever barotrauma is excluded, the underlying disease should be considered as the cause for the pneumomediastinum/subcutaneous emphysema. In fact, obstructive pulmonary diseases and ARDS are known risk factors for the development of pneumomediastinum/subcutaneous emphysema [11]. All of our patients had ARDS, while chronic obstructive pulmonary disease had a low prevalence and was even less frequent in CoV-ARDS than in noCoV-ARDS patients.

Ground-glass opacities, crazy paving appearance, air space consolidation, bronchovascular thickening and dilatation can be seen on CT scans of COVID-19 patients [13]. In addition, patients with pneumomediastinum can have radiological signs of intraparenchymal lesions such as pneumatocele and interstitial emphysema [14]. Pneumomediastinum/subcutaneous emphysema could be attributed to the Macklin effect as seen in figure 1. This pathophysiological process is characterised by alveolar ruptures, air dissection along bronchovascular sheaths and spreading of the pulmonary interstitial emphysema into the mediastinum. The rupture along the alveolar tree releases alveolar air which centripetally dissects through the pulmonary interstitium along the bronchovascular sheaths toward the pulmonary hila $[14,15]$.

The high incidence of pneumomediastinum/subcutaneous emphysema (13\%) observed during the COVID-19 crisis is worrying and deserves a careful assessment. Even though the mortality rate was not significantly different in patients with and without pneumomediastinum/subcutaneous emphysema, future studies should focus on the follow-up of surviving patients who developed pneumomediastinum/subcutaneous emphysema. This is essential in determining its effect on long-term outcomes, such as on lung function or on the development of lung diseases like chronic obstructive pulmonary disease or pulmonary fibrosis [16].

Author contributions: Each author has contributed significantly to, and is willing to take public responsibility for, the following aspects of the study. Design: D.H.L. Lemmers, M. Abu Hilal, C. Bna, G. Natalini. Data Acquisition: D.H.L. Lemmers, M. Abu Hilal, G. Natalini, C. Prezioso, E. Cavallo, N. Nencini, S. Crisci. Analysis: D.H.L. Lemmers, M. Abu Hilal, G. Natalini. Interpretation: D.H.L. Lemmers, M. Abu Hilal, C. Bna, F. Fusina, G. Natalini. Drafting: D.H.L. Lemmers, M. Abu Hilal, G. Natalini, C. Prezioso, E. Cavallo, N. Nencini, S. Crisci, F. Fusina. Critical Revision: D.H.L. Lemmers, M. Abu Hilal, C. Bna, C. Prezioso, E. Cavallo, N. Nencini, S. Crisci, F. Fusina, G. Natalini

Ethical approval: Our referral Ethics Committee approved a waiver of consent for this retrospective study. Protocol number: NP 4142

Conflict of interest: None declared.

\section{References}

1 Acute Respiratory Distress Syndrome Network. Ventilation with lower tidal volumes as compared with traditional tidal volumes for acute lung injury and the acute respiratory distress syndrome. $N$ Engl J Med 2000; 342: $1301-1308$.

2 Fan E, Del Sorbo L, Goligher EC, et al. An Official American Thoracic Society/European Society of Intensive Care Medicine/Society of Critical Care Medicine Clinical Practice Guideline: mechanical ventilation in adult patients with acute respiratory distress syndrome. Am J Respir Crit Care Med 2017; 195: 1253-1263.

3 Slutsky AS, Ranieri VM. Ventilator-induced lung injury. N Engl J Med 2013; 369: 2126-2136.

4 Kouritas V, Papagiannopoulos K, Lazaridis G, et al. Pneumomediastinum. J Thorac Dis 2015; 7: S44-S49. 
5 ARDS Definition Task Force. Acute respiratory distress syndrome: the Berlin Definition. JAMA 2012; 307: 2526-2533.

6 Petersen G, Baier H. Incidence of pulmonary barotrauma in a medical ICU. Crit Care Med 1983; 11: 67-69.

7 Maunder RJ. Subcutaneous and mediastinal emphysema. Pathophysiology, diagnosis, and management. Arch Intern Med 1984; 144: 1447-1453.

8 Gammon RB, Shin MS, Buchalter SE. Pulmonary barotrauma in mechanical ventilation. Patterns and risk factors. Chest 1992; 102: 568-572.

9 Bellani G, Laffey JG, Pham T, et al. Epidemiology, patterns of care, and mortality for patients with acute respiratory distress syndrome in intensive care units in 50 countries. JAMA 2016; 315: 788-800.

10 Ioannidis G, Lazaridis G, Baka S, et al. Barotrauma and pneumothorax. J Thorac Dis 2015; 7: 6.

11 Anzueto A, Frutos-Vivar F, Esteban A, et al. Incidence, risk factors and outcome of barotrauma in mechanically ventilated patients. Intensive Care Med 2004; 30: 612-619.

12 McGuinness G, Zhan C, Rosenberg N, et al. High incidence of barotrauma in patients with COVID-19 infection on invasive mechanical ventilation. Radiology 2020; 297: E252-E262.

13 Ojha V, Mani A, Pandey NN, et al. CT in coronavirus disease 2019 (COVID-19): a systematic review of chest CT findings in 4410 adult patients. Eur Radiol 2020; 30: 6129-6138.

14 Murayama S. Spontaneous pneumomediastinum and Macklin effect: overview and appearance on computed tomography. World J Radiol 2014; 6: 850-854.

15 Wintermark M, Schnyder P. The Macklin effect: a frequent etiology for pneumomediastinum in severe blunt chest trauma. Chest 2001; 120: 543-547.

16 Spagnolo P, Balestro E, Aliberti S, et al. Pulmonary fibrosis secondary to COVID-19: a call to arms? Lancet Respir Med 2020; 8: 750-752. 